\title{
AS DIFERENÇAS ENTRE BRASIL E PORTUGAL NA REGULAMENTAÇÃO DO VAREJO FARMACÊUTICO E OS POSSÍVEIS IMPACTOS NA ESTRATÉGIA COMERCIAL
}

\author{
THE DIFFERENCES BETWEEN BRAZIL AND PORTUGAL IN THE REGULATION OF \\ PHARMACEUTICAL RETAIL AND THE POSSIBLE IMPACTS IN THE COMMERCIAL \\ STRATEGY
}

Leonardo Anacleto Chaves ${ }^{1}$

José Glimovaldo Lupoli Junior ${ }^{2}$

\begin{abstract}
RESUMO: Verificamos no Brasil uma elevada concentração no varejo farmacêutico, com a existência de grandes redes, mas com uma grande participação de redes independentes, gerando elevada competitividade e movendo seus gestores na busca de fidelizar o consumidor, seja pelo preço, produtos, serviços, comodidades que oferecem. Neste ambiente em que o varejo físico, de forma global, vem buscando se reinventar, o varejo farmacêutico está inserido em um ambiente político-legal igualmente ou mais desafiador. Nesse sentido, quando comparamos a regulamentação existente no Brasil com a de Portugal, agregando os dados de mercado e demográficos, se verifica possíveis vantagens e desvantagens do modelo nacional comparativamente ao português.
\end{abstract}

Palavras-chave: Varejo Farmacêutic. Farmácia Comunitária. Regulação de Preços. Direito Regulatório. Farmácia. Drogaria. Medicamento.

ABSTRACT: We observed a high concentration in pharmaceutical retail in Brazil, with the existence of large networks, but with a large participation of independent networks, generating high competitiveness and moving its managers in the search of consumer loyalty, be it for the price, products, services, amenities offer. In this environment where physical retailing has been trying to reinvent itself globally, retail pharmacy is embedded in an equally or more challenging political-legal environment. In this sense, when we compare the existing regulation in Brazil with that of Portugal, aggregating market and

\footnotetext{
'Bacharel em Direito - Faculdade de Direito de Bauru - ITE Instituição Toledo de Ensino Pós-graduação em Direito Tributário - IBPEX - UNINTER

MBA Varejo e Mercado de Consumo - USP ESALQ.E-mail: leo4chaves@gmail.com

${ }^{2}$ Professor do Departamento de Marketing da Universidade de São Paulo USP. Administração pela Universidade de São Paulo - USP. Pós - Graduado in Retailing Management by

Youngstown State University -

Professor e Consultor Associado à Fundação Dom Cabral - FDC.Consultor da Fundação Instituto de Admin istração-FIA. Consultor Senior em Marketing do Programa de Administração de Varejo da FIA LABIFIN/PROVAR. Tenente - Coronel da Força Aérea Brasileira, onde atuou na área de logística aeronáutica.
} 
demographic data, there are possible advantages and disadvantages of the national model compared to the Portuguese one.

Keywords: Pharmaceutical Retail. Community pharmacy. Price Regulation. Regulatory Law. Pharmacy. Drugstore. Drug.

\section{INTRODUÇÃO}

A análise do ambiente competitivo inicia-se necessariamente pela avaliação das tendências do ambiente macroeconômico. E mais importante do que indicadores econômicos de curto prazo (curvas de juros, taxas cambiais, inflação, nível de atividade, taxa de desemprego, déficit nominal), deve-se estar atento a vetores de longo prazo que, por sua vez, influenciam esses mesmos indicadores de curto prazo. Nos tempos atuais, tais vetores incluem: retomada econômica oriental, urbanização descentralizada da riqueza, riscos integrados e globalização plena (MOTTA, 2014).

Ao analisar o vetor de globalização plena, verifica-se, pelo gráfico da Figura ı, que o varejo farmacêutico brasileiro vem em uma constante crescente, e, como consequência, ainda é um mercado que atrai novos investimentos, tanto de novos entrantes, como dos já presentes no mercado (FIA, 2018).

\section{CRESCIMENTO DO VAREJO FARMACÊUTICO BRASILEIRO}

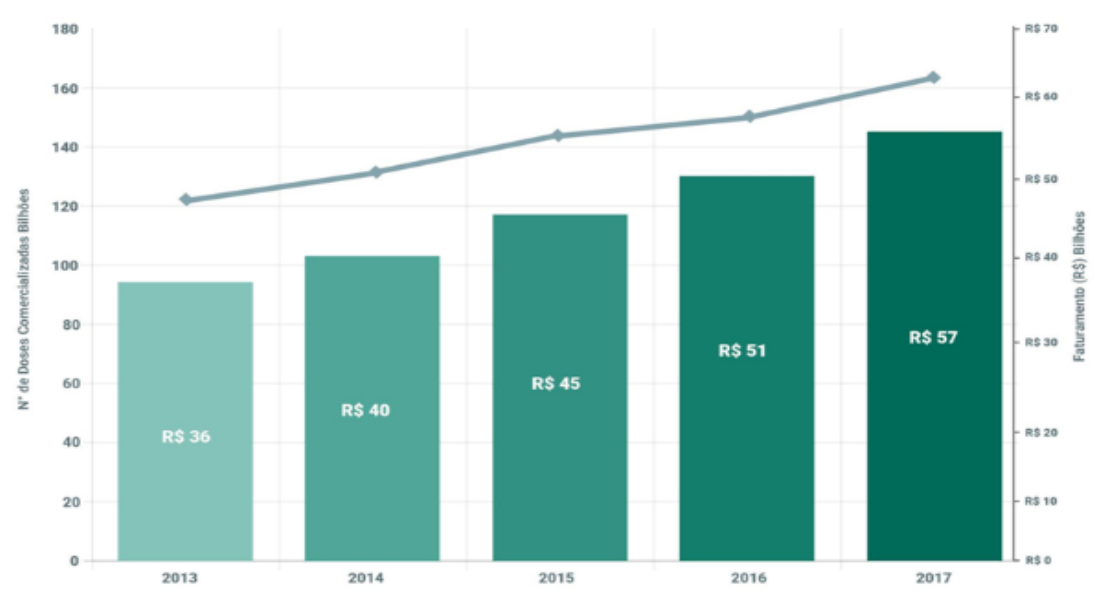

Faturamento (RS) aihnös
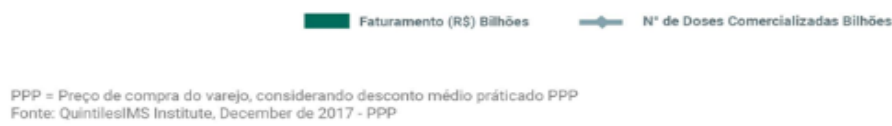

Figurar. Crescimento do varejo farmacêutico brasileiro, de 2013 a 2017.

Fonte: FIA (2018) 
Adicionalmente, segundo estudo (INTERFARMA, 20I8), as projeções de crescimento para o varejo farmacêutico no Brasil para o ano de 2022 indicam que o país atingirá a $5^{\underline{a}}$ posição no ranking global.

\section{RANKING DOS MERCADOS FARMACÊUTICOS}
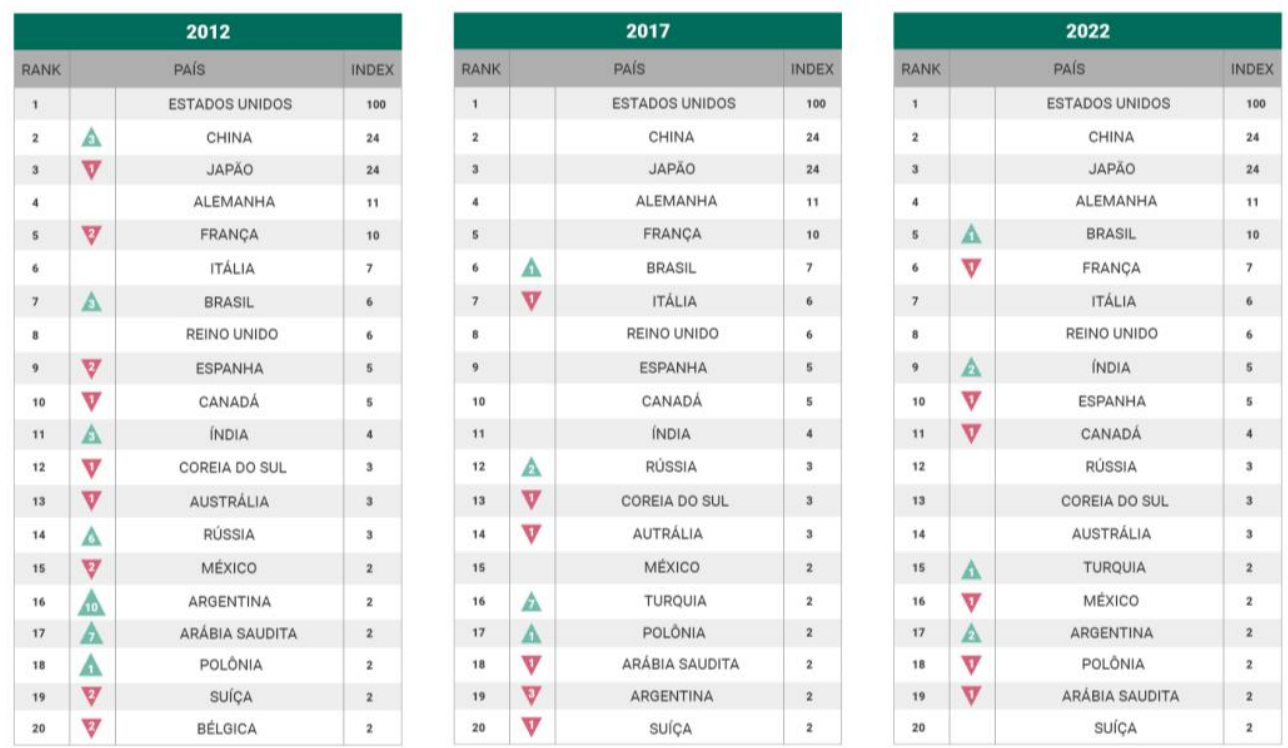

Figura 2. Ranking dos mercados farmacêuticos, 2012, 2017e projeção de 2022 Fonte: INTERFARMA (2018)

Apesar dos números do consumo brasileiro apresentarem-se em crescimento, outro fator que vem sendo ressaltado é a quantidade de estabelecimentos abertos ao longo dos últimos anos, que poderiam ocasionar um excesso de competição (PEREIRA, 2017).

Segundo dados de 2018 do Conselho Federal de Farmácia (CFF, 2018), o Brasil possui 87.794 farmácias e drogarias privadas, distribuídas pelo país conforme demonstrado na Tabela I.

Tabela I. Quantidade de farmácias e drogarias no Brasil em 2018

\begin{tabular}{l|l}
\hline UF & Farmácia/Drogarias Privadas \\
\hline Região Norte & 6.628 \\
\hline Acre & 272 \\
\hline Amapá & 239 \\
\hline Amazonas & 1.330 \\
\hline Pará & 3.041 \\
\hline Rondônia & 704 \\
\hline Roraima & 197 \\
\hline Tocantins & 845 \\
\hline Região Nordeste & 21.047 \\
\hline
\end{tabular}




\begin{tabular}{l|l}
\hline Alagoas & $\mathrm{I} .425$ \\
\hline Bahia & 4.424 \\
\hline Ceará & 2.908 \\
\hline Maranhão & 3.015 \\
\hline Paraíba & $\mathrm{I} .439$ \\
\hline Pernambuco & 3.277 \\
\hline Piauí & 2.133 \\
\hline Rio Grande do Norte & $\mathrm{I} .493$ \\
\hline Sergipe & 933 \\
\hline Região Sudeste & 37.432 \\
\hline Espírito Santo & 2.031 \\
\hline Minas Gerais & 9.843 \\
\hline Rio de Janeiro & 7.358 \\
\hline São Paulo & $\mathrm{I} 8.200$ \\
\hline Região Sul & 14.038 \\
\hline Paraná & 5.031 \\
\hline Santa Catarina & 3.617 \\
\hline Rio Grande do Sul & 5.390 \\
\hline Região Centro-Oeste & 8.649 \\
\hline Distrito Federal & $\mathrm{I} .541$ \\
\hline Goiás & 4.106 \\
\hline Mato Grosso & $\mathrm{I} .830$ \\
\hline Mato Grosso do Sul & $\mathrm{I.172}$ \\
\hline Brasil & 87.794 \\
\hline Car & \\
\hline
\end{tabular}

Fonte: CFF (2018)

Em se pensando em globalização plena, inclusive com uma possível internacionalização do modelo de varejo brasileiro, partimos para uma análise do ambiente de negócios, onde o ambiente político-legal é de suma importância.

No segmento do varejo farmacêutico, dado o entendimento, pelo poder público, de potencial impacto na saúde da população, verifica-se (SEBRAE, 2019) que no Brasil há uma complexa legislação que regulamenta: a) os produtos permitidos para comercialização em tais estabelecimentos; b) quais estabelecimentos estão autorizados a comercializar medicamentos; c) fixação de uma precificação máxima; entre outras regulamentações.

Percebe-se que, apesar de apresentar números financeiros positivos, o mercado brasileiro, em termos de boas práticas farmacêuticas, foi considerado como um mercado desregulado, segundo o "Estudo do Sector das Farmácias em Portugal” conduzido pelo Centro de Estudos e Investigação em Saúde da Universidade de Coimbra (CEISUC, 2006) e contratado pela Ordem dos Farmacêuticos de Portugal [OF]. 
Assim, como objetivo geral buscou-se analisar a forma como as forças do macroambiente (político-legal) influenciaram o desenvolvimento do varejo farmacêutico brasileiro e português. Já como objetivos específicos foram: compreender o macroambiente de Portugal para uma eventual internacionalização de varejo brasileiro; analisar os pontos fortes, os pontos fracos, as oportunidades e as ameaças da regulamentação portuguesa, bem como, se tais regulamentações afastariam ou atrairiam eventuais investimentos.

Ao alcançar tais objetivos, os resultados contribuem de forma prática, por exemplo, para decidir-se gerencialmente por uma expansão ou internacionalização do negócio, ou, ainda, academicamente propor mudanças regulatórias no setor, de modo a alcançar uma dispensação de medicamentos mais consciente.

Deste modo, onde a internacionalização do varejo constitui-se como um processo de identificação de oportunidades, e não somente de limitações atingidas no mercado doméstico, e, ainda, que a dimensão reguladora pode favorecer ou criar barreiras para novos entrantes (MADEIRA; SILVEIRA, 20I2), justifica-se, portanto, o presente trabalho por viabilizar esta análise.

\section{Material e Métodos}

Através de pesquisa exploratória, buscou-se maior familiaridade com o problema, de modo a explicitá-lo para construir-se hipóteses (MATTAR, 2014).

Para levantamento dos dados foi utilizado o método de levantamento em fontes secundárias, através de: a) levantamento bibliográfico, com base em material já publicado; b) levantamento de estatísticas, pois é importante estar sempre atento e buscar estatísticas que possam ajudar no delineamento do problema de pesquisa; e c) levantamento de pesquisas realizadas, verificando se já foram efetuadas pesquisas sobre o tema em estudo (GIL, 2or8; MATTAR, 2014).

Pilati (2000) nos ensina que para promover o estudo comparado no Direito é necessário previamente definir e conhecer os dois campos que serão analisados, ou seja, a parte do Direito nacional e a parte do Direito estrangeiro que serão objetos de estudo. Assim, nesse tipo de investigação você poderá verificar a inferioridade ou a superioridade de atributos entre um elemento e aquele que lhe serve de termo de comparação.

\section{Resultados e Discussão}

\section{Análise do Macroambiente}


Kotler (2012) diz que as empresas devem monitorar seis importantes forças macroambientais: demográfica, econômica, sociocultural, natural, tecnológica e políticolegal. Tais forças serão descritas separadamente, mas é preciso lembrar que suas interações levarão a novas oportunidades e ameaças.

Nesse sentido foi observado alguns destes ambientes para melhor compreensão dos países.

\section{Ambiente Demográfico}

Os desdobramentos demográficos costumam ocorrer em um ritmo previsível, onde o principal indicador é a população.

Quando se observa o crescimento da população dos dois países, se observa um decréscimo em Portugal, contra um crescimento no Brasil

\begin{tabular}{|c|c|c|c|c|c|c|c|c|c|c|}
\hline & 1990 & 2000 & 2010 & 2011 & 2012 & 2013 & 2014 & 2015 & 2016 & 2017 \\
\hline Brazil & $149,352,145.0$ & $175,287,587.0$ & $196,796,269.0$ & $198,686,688.0$ & $200,560,983.0$ & $202,408,632.0$ & $204,213,133.0$ & $205,962,108.0$ & $207,652,865.0$ & $209,288,278.0$ \\
\hline Portugal & $9,983,218.0$ & $10,289,898.0$ & $10,573,100.0$ & $10,557,560.0$ & $10,514,844.0$ & $10,457,295.0$ & $10,401,062.0$ & $10,358,076.0$ & $10,325,452.0$ & $10,300,300.0$ \\
\hline
\end{tabular}

Figura 3. População Total de Brasil e Portugal

Fonte: World Bank (2019)

Outro dado demográfico que tem se verificado globalmente é o envelhecimento da população. Em 1950, havia apenas I3I milhões de pessoas com 65 anos ou mais, em 1995, esse número quase triplicou, chegando a 371 milhões. Em 2050, uma em cada dez pessoas no mundo terá 65 anos ou mais (Kotler e Keller, 2012).

Tal fato se deve ao aumento da expectativa de vida, conforme se verifica também no Brasil (75 anos) e em Portugal (8r anos).

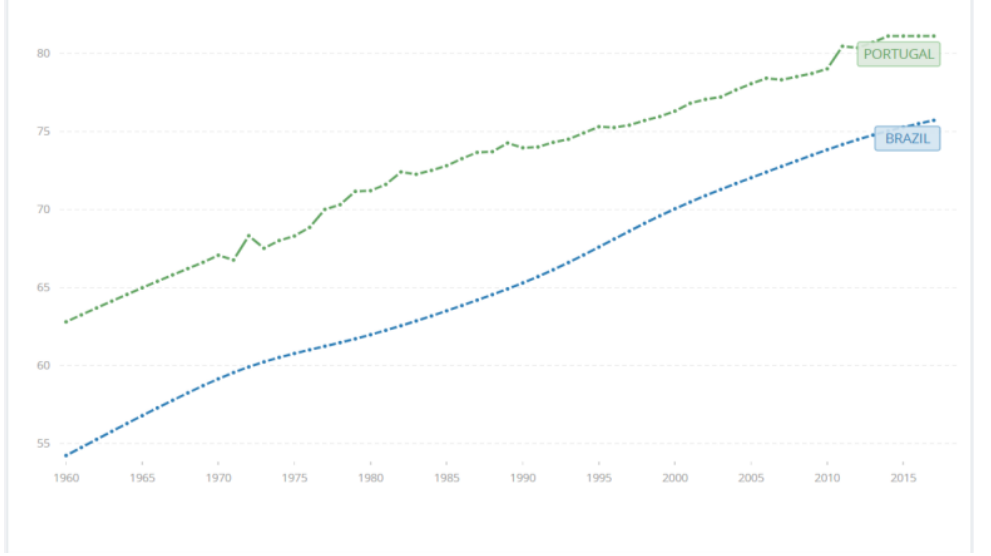

Figura 4. Expectativa de vida de Brasil e Portugal - 1960 a 2017 Fonte: World Bank (2019) 


\section{Ambiente Econômico}

O poder de compra em uma economia depende da renda, dos preços, da poupança, do endividamento e da disponibilidade de crédito. Como a recente crise econômica demonstrou, as tendências que afetam o poder de compra podem ter um forte impacto nos negócios, especialmente no caso de produtos dirigidos a consumidores de alto poder aquisitivo e aos sensíveis a preço (Kotler e Keller, 2012).

Nesse sentido passamos a analisar alguns indicadores econômicos de Brasil e Portugal, temos os seguintes comparativos:

\begin{tabular}{lccc}
\hline Country & Most Recent Year & Most Recent Value \\
\hline Brazil & 2018 & 3.7 & M. \\
Portugal & 2018 & 1.0
\end{tabular}

Figura 5. Inflação (\%), Brasil e Portugal - 2018 Fonte: World Bank (2019)

\begin{tabular}{|lcc}
\hline Country & Most Recent Year & Most Recent Value \\
\hline Brazil & 2018 & 15,820 \\
\hline Portugal & 2018 & 33,200 \\
\hline
\end{tabular}

Figura 6. Renda per capita (Dólar), Brasil e Portugal Fonte: World Bank (2019)

\begin{tabular}{|lcc} 
Country & Most Recent Year & Most Recent Value \\
\hline Brazil & 2018 & 12.3 \\
\hline Portugal & 2017 & 8.9 \\
\hline
\end{tabular}

Figura 7. Taxa de Desemprego, Brasil e Portugal Fonte: World Bank (2019)

\begin{tabular}{|lrl}
\hline Country & Most Recent Year & Most Recent Value \\
\hline Brazil & 2018 & 113.7 \\
Portugal & 2018 & 149.6
\end{tabular}

Figura 8. Crédito interno fornecido pelo setor financeiro (\%PIB), Brasil e Portugal Fonte: World Bank (2019) 


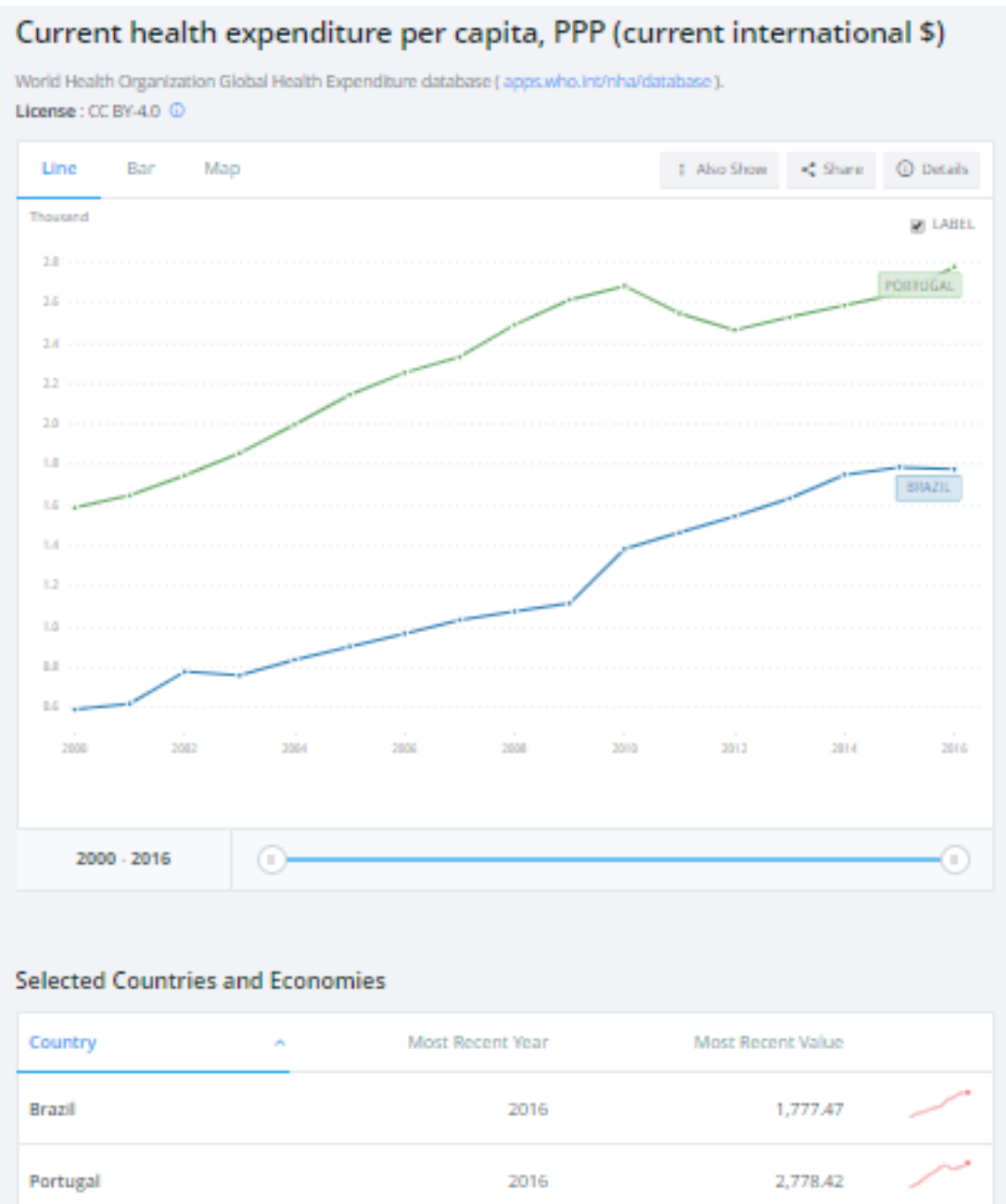

Figura 9. Gasto com Saúde per capita (Dólar), Brasil e Portugal Fonte: World Bank (2019)

\section{Ambiente Tecnológico}

Ao se observar avanços tecnológicos nos estabelecimentos de varejo farmacêutico, ainda vemos poucos avanços disruptivos, devido aos controles regulatórios existentes, inclusive no tradicional, e já existente, comércio eletrônico.

Nesse sentido, foi observado que, ao contrário do Brasil, Portugal tem investido nesta área, com a aprovação, em 2017, da Estratégia Nacional para o Ecossistema de Informação de Saúde 2020, que visa o aumento do uso pessoal, autónomo e participado dos cidadãos. Para isso, prevê a disponibilização de múltiplas plataformas de serviços digitais que permitem o acesso e partilha de informação, mas também a simplificação e desmaterialização de registos e processos no Sistema Nacional de Saúde [SNS], até 2020. 
Nesse sentido, foi criado um portal para os cidadãos portugueses se cadastrarem e acompanharem suas informações, criaram o Registro de Saúde Eletrônico (informações clínicas essenciais do cidadão), além de Aplicativos para Celular (App).

Em 2017 foi implantado a prescrição e dispensação de medicamentos eletrônica, que entre outras coisas, permite também saber se há números de celular a receber mais de cinco mensagens por dia provenientes da Receita Sem Papel, qual o número de prescritores com mais de cem embalagens dispensadas na mesma farmácia e no mesmo dia, ou a quantidade de dispensas efetuadas, por farmácia, quando o prazo de validade está prestes a terminar.

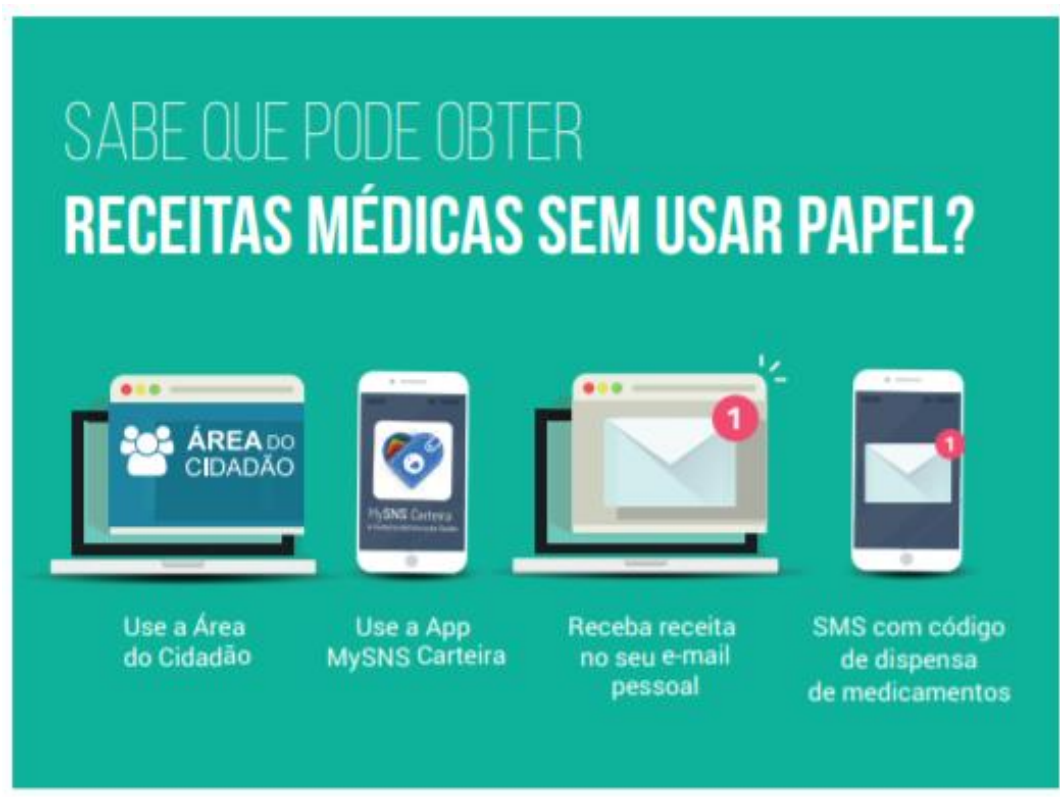

Figura io. Sistema Receita sem Papel, Portugal

Fonte: SNS (2018)

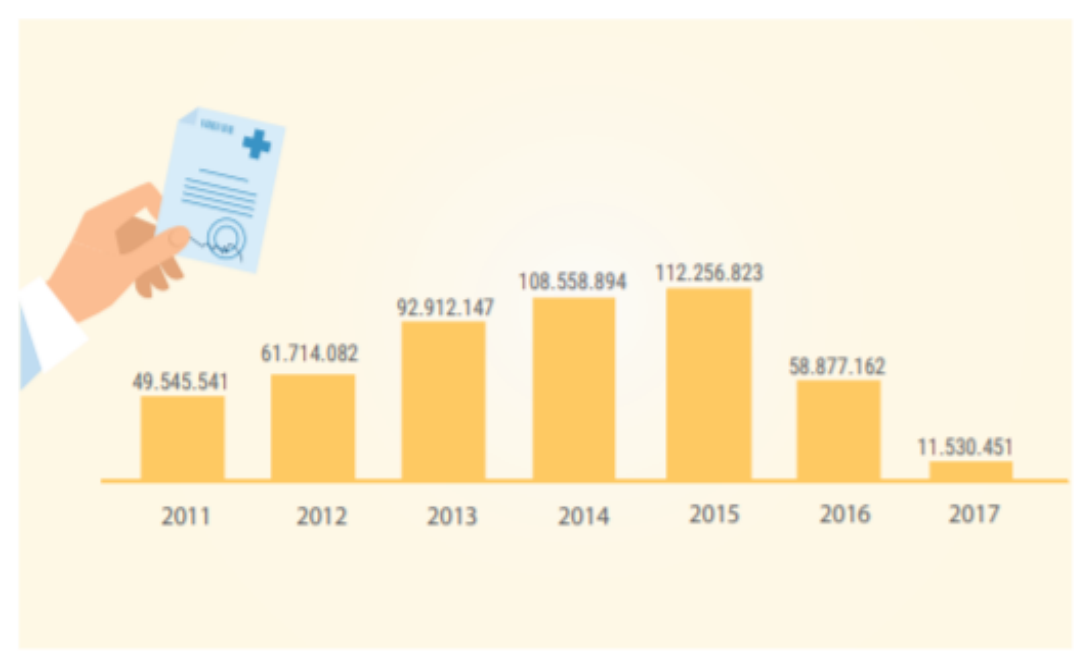

Figura II. Receitas em Papel, Portugal

Fonte: SNS (2018) 


\section{Ambiente Político}

Em termos de política de saúde, ambos os países consideram as farmácias como unidade de saúde, como ponto de contato com os cidadãos para a dispensação de medicamentos e prestação de serviços farmacêuticos.

Ambos os países também possuem políticas de coparticipação para subsídio de medicamentos, de modo a viabilizar o acesso à saúde/medicamentos a todas as classes sociais.

No Brasil o programa é conhecido como Farmácia Popular e, diferentemente do que ocorre em Portugal, que todas as farmácias participam, por aqui a participação da rede privada ocorre por adesão.

No Brasil o orçamento para esse programa de subsídio vem reduzindo, inclusive com fechamento de estabelecimentos da rede própria, conforme mostra a Figura ir e i2.

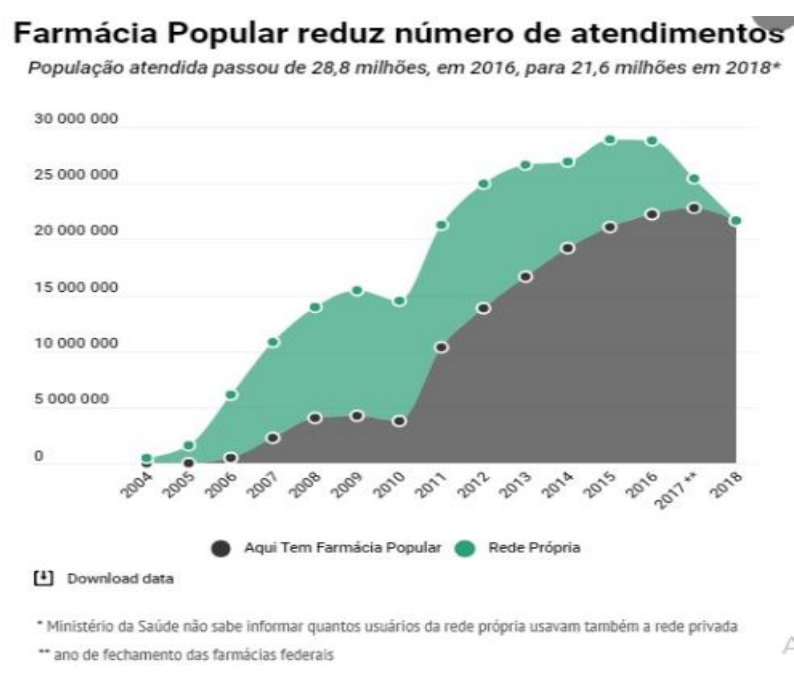

Figura 12. Redução número atendimentos Farmácia Popular, Brasil Fonte: Instituto Humanitas Unisinos (2019)

Em R\$ bilhöes

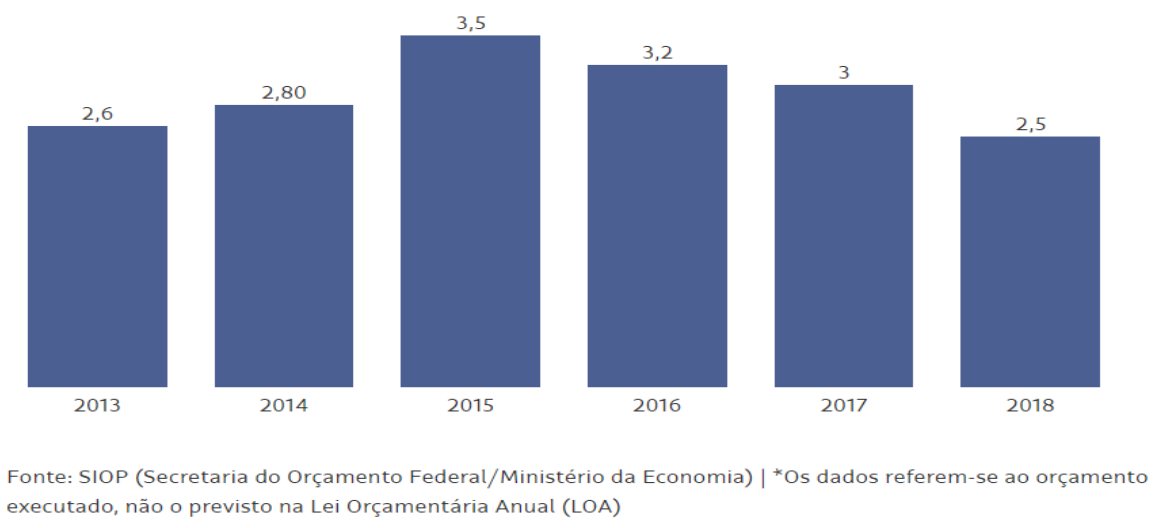

Figura 13. Orçamento Farmácia Popular, Brasil Fonte: JUNQUEIRA (2019) 
Em Portugal, os medicamentos sujeitos a receita médica e não sujeitos a receita médica coparticipados, fortemente regulados pelo Estado de forma a evitar distorções à concorrência que prejudiquem os cidadãos, representam cerca de $75 \%$ do volume de vendas da farmácia média. Por essa razão, a economia da farmácia é altamente dependente das políticas farmacêuticas (ANTÃO; GRENHA, 2016).

\section{Ambiente Político-Legal}

Em se tratando a legislação regulatória como uma ameaça externa do macroambiente de Negócios, entende-se ser de suma importância a sua vigilância, inclusive como exercício de inteligência de mercado.

A regulamentação dos negócios, segundo Kotler e Keller (2006), possui três propósitos centrais: I - proteção de concorrência desleal; 2 - proteção do consumidor contra práticas desleais; e 3 - proteção da sociedade de comportamentos desenfreados das empresas.

Continuam (KOTLER; KELLER, 2006) trazendo o questionamento de até que ponto que os custos da regulamentação são maiores que os benefícios.

O poder público deve encontrar o ponto de equilíbrio no cumprimento da lei sem ser negligente ou excessivamente zeloso.

Fechando o raciocínio (KOTLER; KELLER, 2006), apontam que embora cada nova lei possa ter uma justificativa legítima, a legislação pode ter o efeito imprevisto de minar iniciativas e retardar o crescimento econômico.

Antigamente adotava-se a postura de que o investidor é que era o detentor do conhecimento, agindo-se muito de dentro para fora da empresa, mas atualmente o mercado passa a ser o orientador e regulador dos investimentos (KOTLER, 2000).

Nesse sentido, analisando possíveis movimentações de internacionalização, assim como possível propositura de implementação da legislação regulatória portuguesa para o Brasil, faz-se necessário o estudo e mapeamento comparativo de seus principais pontos para o Varejo Farmacêutico.

\section{Regulamentação de quem pode ser dono de uma Farmácia}

A modalidade mais comum para Farmácias e Drogarias ainda é o varejo com loja física, apesar das vendas online existirem, ainda representa muito pouco diante do modelo tradicional (FEBRAFAR, 2019). 
Não foi localizada qualquer restrição na legislação brasileira sobre quem poderia ser dono de uma farmácia, com isso, hoje é possível se verificar uma forte presença de faturamento das grandes redes, mas ainda uma forte presença em quantidade de lojas dos independentes, numa relação de alta competitividade, onde o consumidor acaba por ser beneficiado.

Conforme dados divulgados pela Associação Brasileira de Redes de Farmácias e Drogarias (ABRAFARMA, 2018), 9,3\% das farmácias abertas são de seus associados, mas que, quando analisado na proporcionalidade do total do faturamento, representavam 4I,2\% do faturamento total do segmento.

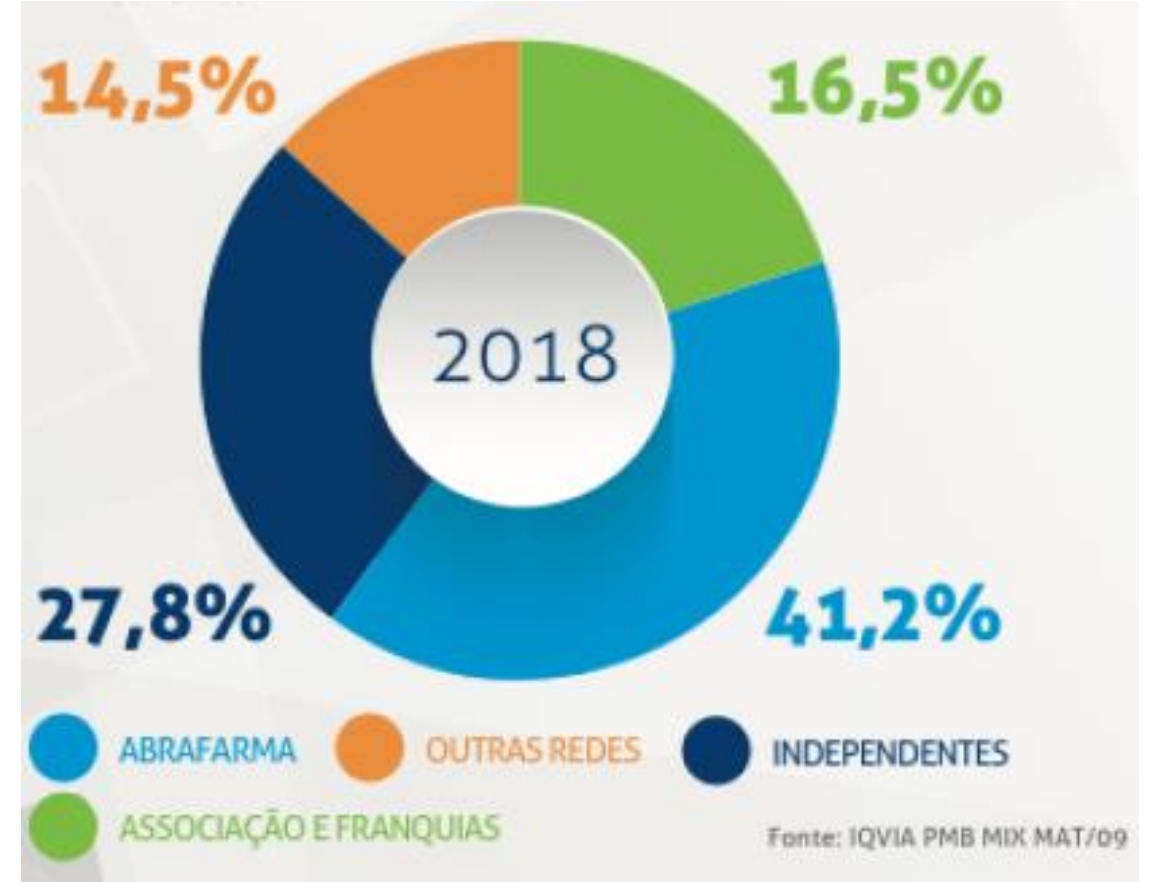

Figura 14. Representatividade dos associados da Associação Brasileira de Redes de Farmácias e Drogarias [ABRAFARMA]

Fonte: ABRAFARMA (2019)

No entanto, historicamente em Portugal, por meio de Decreto Lei (Portugal, 1933), foi restringida a propriedade de uma Farmácia exclusivamente aos Farmacêuticos.

Neste desenho, como cada farmacêutico poderia ter somente um estabelecimento, estabeleceu-se um cenário de baixa competitividade, onde a legislação regulava a possibilidade de novos entrantes. 
Em material contratado pela Ordem dos Farmacêuticos (CEISUC, 2006), o regime de propriedade de farmácia na Europa em 2006 tinha a configuração demonstrada na figura 5 .

\begin{tabular}{|l|l|l|l|}
\hline \multirow{2}{*}{ Propriedade das Farmácias } & \multicolumn{3}{|c|}{ Países } \\
\hline \multirow{5}{*}{ Exclusiva de Farmacêuticos } & Alemanha & Áustria & Bulgária \\
\cline { 2 - 4 } & Chipre & Dinamarca & Eslováquia \\
\cline { 2 - 4 } & Eslovénia & Espanha & Finlândia \\
\cline { 2 - 4 } & França & Grécia & Hungria \\
\cline { 2 - 4 } & Itália & Letónia & Luxemburgo \\
\cline { 2 - 4 } & Portugal & Turquia & \\
\hline \multirow{2}{*}{ Não exclusiva de Farmacêuticos } & Bélgica & Croácia & Estónia \\
\cline { 2 - 4 } & Holanda & Irlanda & Lituânia \\
\cline { 2 - 4 } & Malta & Noruega & Polónia \\
\cline { 2 - 4 } & Reino Unido & República Checa & Suiça \\
\hline
\end{tabular}

Figura 15. Regime de propriedade de farmácia no espaço europeu Fonte: CEISUC (2006)

Em maio de 2005, em seu discurso de posse, o Primeiro Ministro de Portugal, José Sócrates Carvalho Pinto de Sousa, anunciou que iria "enfrentar o lobby das farmácias", desregulamentando o setor (BRANDÃO, 2010).

Mas tal cenário em Portugal somente foi alterado em 3I de agosto de 2.007, por meio do Decreto-Lei 307, onde se excluiu a limitação à propriedade apenas a farmacêuticos.

A expectativa foi de se criar um ambiente que proporcionasse a entrada de novos investimentos, aberturas de novas farmácias e um ambiente concorrencial quase inexistente até então.

O mesmo Decreto-Lei 307, no entanto, também estabelece em seu artigo 16º algumas incompatibilidades para se exercer a propriedade de farmácias, a exemplo de profissionais de saúde prescritores de medicamentos, associações, distribuidores e indústrias.

\section{Regulamentação quanto à quantidade de Farmácias por proprietário}

No Brasil não encontramos restrições à quantidade de estabelecimentos/farmácias por proprietário, pelo contrário, verifica-se, conforme quadro anteriormente exposto, uma grande concentração do mercado em grandes redes. 
Destas 87.794 registradas no Conselho Federal de Farmácia [CFF], apenas 78,5 mil delas apresentaram faturamento nos levantamentos realizados pela empresa global de pesquisa clínica IQVIA, conforme Figura 5.

Em 3i de dezembro de 20I8, as 25 redes associadas à Associação Brasileira de Redes de Farmácias e Drogarias [ABRAFARMA] tinham 7.400 mil lojas em todos os estados brasileiros mais Distrito Federal, onde a primeira colocada sozinha possui mais de i8oo lojas.

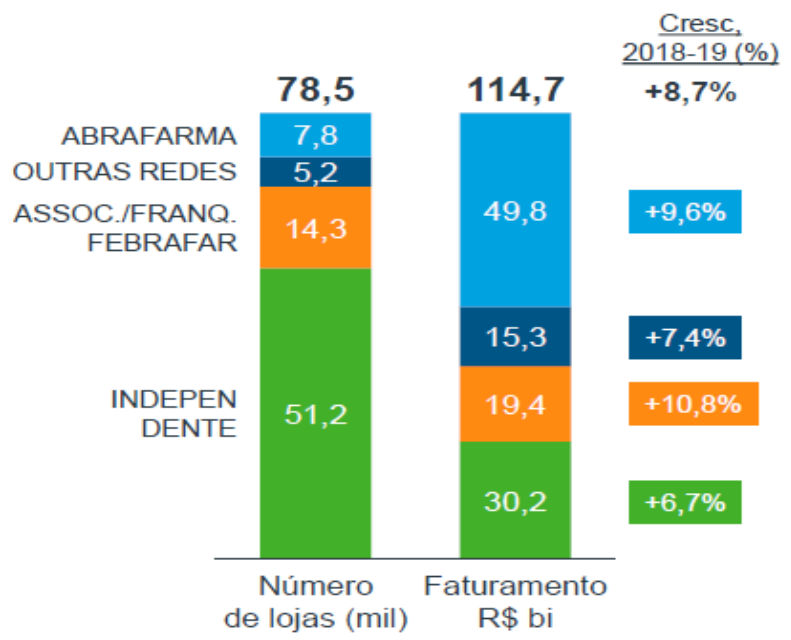

Figura I6. Farmácias no Brasil por tipo de rede e de seu faturamento, em abril de 2019

Fonte: IQVIA Estudo de distribuição - IQVIA World Review 2019 Brasil

\begin{tabular}{|c|c|c|c|c|c|c|c|}
\hline 2018 & 2017 & Grupos Econômicos & UF & 2018 & 2017 & $\begin{array}{l}\text { Grupos } \\
\text { Econômicos }\end{array}$ & UF \\
\hline 1 & 1 & Raia Drogasil & SP & 13 & 12 & Farma Ponte & SP \\
\hline 2 & 2 & $\begin{array}{l}\text { Drogaria Pacheco São } \\
\text { Paulo }\end{array}$ & BR & 14 & 13 & $\begin{array}{l}\text { Farmácia } \\
\text { Permanente }\end{array}$ & AL \\
\hline 3 & 3 & $\begin{array}{l}\text { Farmácias Pague } \\
\text { Menos }\end{array}$ & $\mathrm{CE}$ & 15 & 14 & Farmácia Indiana & $M G$ \\
\hline 4 & 4 & Farmácias São João & RS & 15 & 15 & Drogaria Moderna & RJ \\
\hline 5 & 6 & Extrafarma & PA & 17 & 15 & Drogão Super & SP \\
\hline 6 & 5 & Panvel & RS & 18 & 18 & Drogaria Venâncio & RJ \\
\hline 7 & 8 & Drogaria Nissei & PR & 19 & 21 & Redepharma & PB \\
\hline 8 & 9 & Drogaria Araújo & MG & 20 & 19 & Drogaria São Bento & MG \\
\hline 9 & & Drogarias Globo & $\mathrm{PI}$ & 21 & 23 & $\begin{array}{l}\text { Drogaria Minas } \\
\text { Brasil }\end{array}$ & MG \\
\hline 10 & 11 & Drogal Farmacêutica & SP & 22 & 22 & $\begin{array}{l}\text { Farmácias Vale } \\
\text { Verde }\end{array}$ & PR \\
\hline 11 & 10 & D1000 Varejo Farma & SP & 23 & 24 & $\begin{array}{l}\text { Farmácia Santa } \\
\text { Lúcia }\end{array}$ & ES \\
\hline 12 & & Grupo Tapajós & AM & 24 & 25 & A Nossa Drogaria & RJ \\
\hline
\end{tabular}

Figura 17. Ranking Abrafarma: Número de Lojas (Grupos) em dezembro de 2018 Fonte: GUIA DA FARMACIA (2019) 
Em sentido contrário, Portugal regulamenta e impõe limites, onde por meio do Decreto-Lei n. ${ }^{\mathrm{o}} 307 / 2007$ estabelece em seu artigo $15^{\underline{0}}$ que nenhuma pessoa singular ou sociedade comercial pode deter ou exceder, em simultâneo, direta ou indiretamente, a propriedade, a exploração ou a gestão de mais de quatro farmácias.

\section{Regulamentação para abertura ou encerramento de uma Farmácia}

No Brasil, as regulamentações tendem a seguir o plano piloto de cada município, delimitando eventuais áreas de comércio e/ou exclusivamente residenciais.

Nesse sentido, uma vez atendidos os critérios objetivos do plano piloto e o estabelecido pela Agência nacional de Vigilância Sanitária [ANVISA] e/ou pela Vigilância Sanitária Municipal, poderíamos chegar a um cenário de se abrir quantas farmácias se comporte em determinada rua ou bairro, sem constar nenhuma restrição na legislação brasileira quanto à quantidade ideal, à distância entre elas, tampouco quanto ao encerramento de suas atividades.

No entanto, em Portugal, conforme se verifica do Decreto-Lei 307, citado anteriormente, e no site da Autoridade Nacional do Medicamento e Produtos de Saúde, I. P. [INFRAMED], o licenciamento de novas farmácias é precedido de um procedimento concursal que permita a pré-seleção dos candidatos que preencham os requisitos fixados no respectivo aviso de abertura (INFRAMED, 2019).

A Portaria n. 352/2012, de 30 de outubro, estabelece mais condições gerais de instalação das novas farmácias, como: a) a capitação mínima de 3500 habitantes por farmácia aberta ao público no município, salvo quando a farmácia é instalada a mais de $2 \mathrm{Km}$ da farmácia mais próxima; b) Distâncias mínimas de $350 \mathrm{~m}$ entre farmácias, contados, em linha reta, dos limites exteriores das farmácias; c) Distâncias mínima de Ioo m entre a farmácia e as unidades de saúde, salvo em localidades com menos de 4000 habitantes.

Não bastasse, o Decreto-Lei 307 ainda determina que as farmácias só podem encerrar suas atividades após comunicação a Autoridade Nacional do Medicamento e Produtos de Saúde, I. P. [INFRAMED] com a antecedência mínima de 90 dias.

Se o encerramento for gravemente lesivo ao interesse público a Autoridade Nacional do Medicamento e Produtos de Saúde, I. P. [INFRAMED] pode vir a notificar o proprietário para manter a farmácia em funcionamento. 


\section{Regulamentação do que se pode vender em uma Farmácia ou fora dela}

No Brasil ainda não há previsão legal para venda de medicamentos fora das Farmácias, no entanto, além da IN 09/2009 da Agência nacional de Vigilância Sanitária [ANVISA], há uma série de legislações estaduais e/ou municipais que vedam itens, não medicamentos, que não se podem vender dentro de uma Farmácia.

Verificamos o quão complexo pode ser, no Brasil, o controle do sortimento de itens não farmacêuticos para o gestor de uma rede de farmácias de alcance nacional.

A título de exemplo, apenas os Estados de Pernambuco e de Rondônia regulamentaram a venda de recarga de celular, mas quando falamos de bebidas não alcoólicas o Estado de São Paulo regulamentou apenas água mineral, enquanto em Santa Catarina regulamentou apenas chás.

Quando falamos de itens de conveniência, os Estados do Paraná e de Minas Gerais permitiram, mas não exemplificaram, nem nominaram o que seria permitido.

Em Portugal, a regulamentação do que se pode vender em uma farmácia vem através do artigo $33^{\circ}$ do Decreto-Lei 307/2007, não sendo muito diferente do que é permitido no Brasil. O que chama a atenção é que em i6 de agosto de 2.005, através do Decreto Lei 134, os portugueses, de modo a ampliar o acesso da população aos medicamentos isentos de prescrição e elevar a concorrência, liberaram a venda destes itens nas cadeias de hipermercados.

Em 2014 ainda existiam I.013 locais de venda de medicamentos não sujeitos a receita médica (MNSRM), o que correspondia a 35\% do total de farmácias do país, concorrendo diretamente com as farmácias neste segmento de mercado (ANTÃO, GRENHA, 2016).

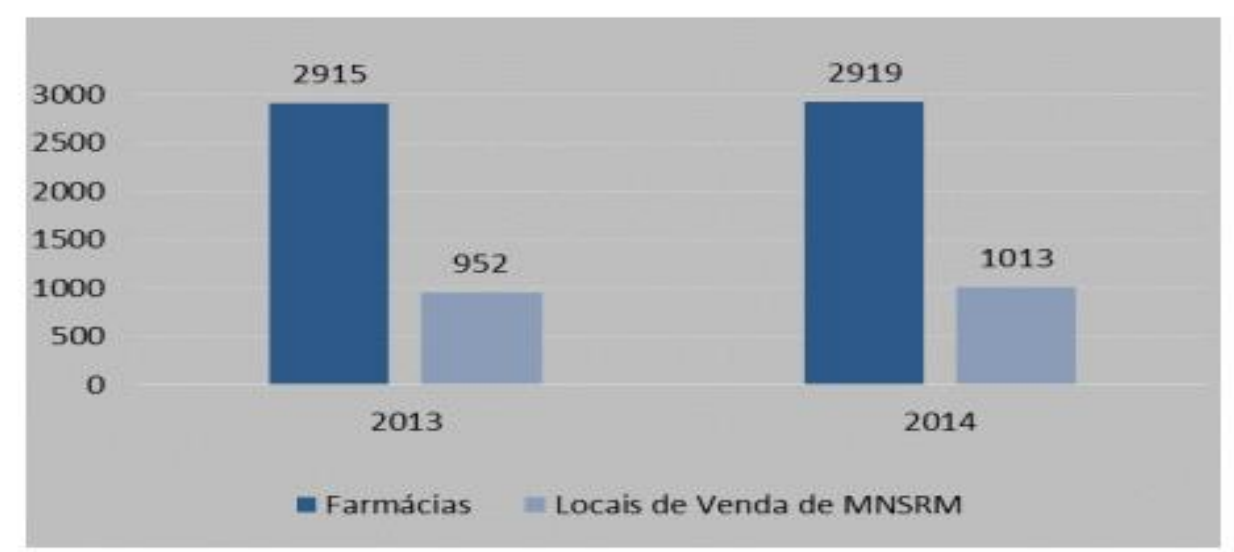

Figura 18. Quantidade de Farmácias e locais de venda de medicamentos não sujeitos a receita médica em Portugal, 2013 e 2014

Fonte: ANTÃO, GRENHA (2016) 
Não bastasse, por meio do Decreto Lei 171/2.012 a farmácia ficou obrigada a dispor de 3 (três) dos 5 (cinco) medicamentos com preço mais baixo em cada um dos grupos

Como consequência desta alteração regulatória, as farmácias portuguesas sofreram quedas de faturamento pela perda do monopólio de venda destes itens.

Tal impacto fica evidente quando analisamos a queda no número de Farmácias em Portugal em 2013, comparado à 2012, ano de implementação da medida.

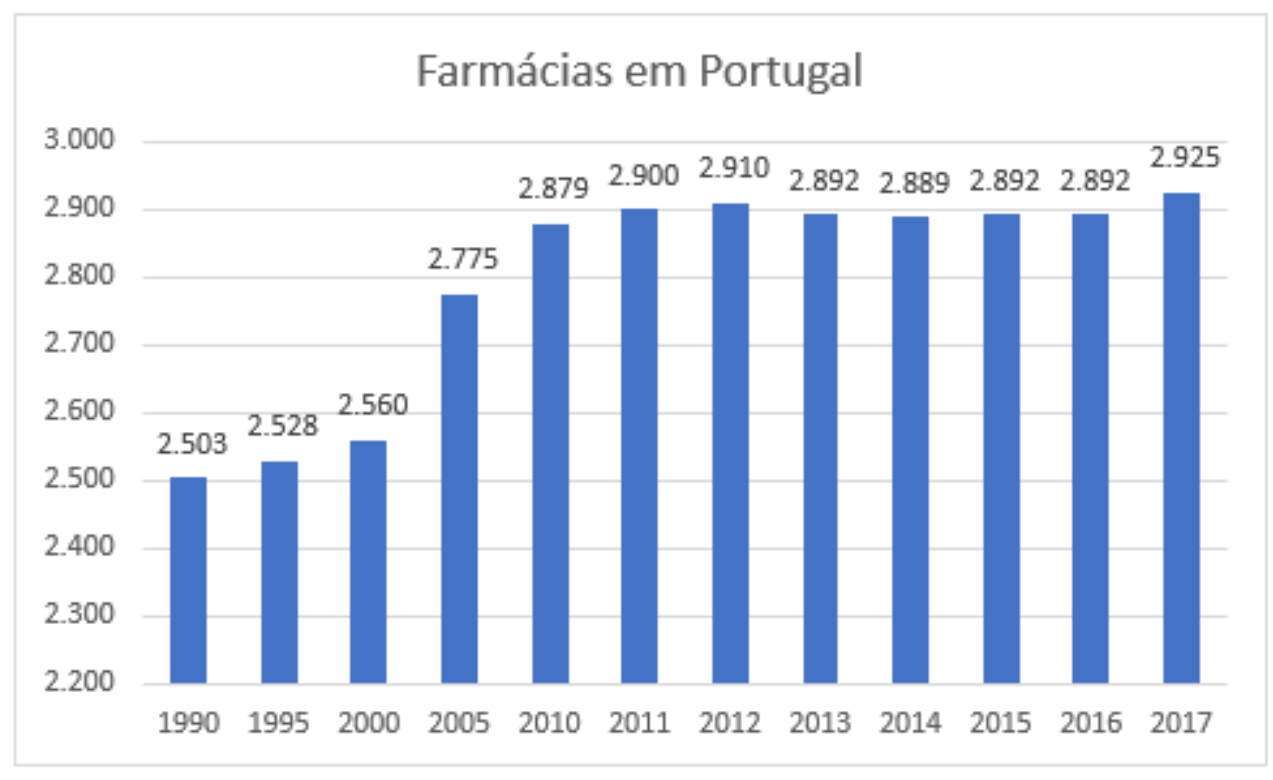

Figura 19. Quantidade de Farmácias em Portugal, 1990 a 2017 Fonte: PORDATA (2019)

\section{Regulamentação do preço de venda para medicamentos}

No Brasil a Agência nacional de Vigilância Sanitária - ANVISA é a responsável pela regulamentação do setor e, através da Câmara de Medicamentos - CMED, todos os anos no mês de março regulamenta o reajuste de preços dos medicamentos.

$\mathrm{Na}$ atual Resolução 02/2019 a Câmara de Medicamentos - CMED determina qual é o preço teto para os fabricantes e distribuidores (Preço Fábrica), como também determina a margem para o preço teto a ser praticado pelas farmácias (Preço Máximo ao Consumidor), mas que mesmo assim, garante uma margem média de 38\%.

Em Portugal, por sua vez, a legislação vem sendo imposta de forma a minimizar os gastos do Estado nos medicamentos com coparticipação, além de maximizar a competição entre as farmácias, que vem ocasionando alguns desequilíbrios no setor. 
O Decreto Lei 65/2.007 permitiu a concessão de descontos em medicamentos com coparticipação do Estado.

Em 2010 houve uma redução da transferência das margens das farmácias através do Decreto Lei 48/2010, e entre outros, o Decreto Lei 19/2014, que alterou o regime de margens máximas de comercialização estrangulou um pouco mais a situação do setor,

Segundo estudo da Universidade de Aveiro (ANTÃO, GRENHA, 2016), os anos de 2013 e 2014 foram aqueles em que se observou um maior número de encerramentos de farmácias, período em que encerraram 46 farmácias e reabriram apenas 13.

\begin{tabular}{|l|c|c|c|c|}
\hline & \multicolumn{2}{|c|}{2013} & 2014 \\
\hline $\begin{array}{l}\text { Encerramento / Reabertura de } \\
\text { Farmácias }\end{array}$ & Encerramento & Reabertura & Encerramento & Reabertura \\
\hline & 29 & 11 & 17 & 2 \\
\hline Farmácias em Insolvência / Penhora & Insolvência & Penhora & Insolvência & Penhora \\
\hline
\end{tabular}

Figura 20. Quantidade de Farmácias que foram abertas, fechadas, com Insolvência e penhora em Portugal, 2013 e 2014 Fonte: ANTÃO, GRENHA (2016)

Em dezembro de 2014, 492 farmácias, 16,9\% das farmácias do país, encontravam-se em situação de insolvência ou penhora, o que representa um crescimento de IO2 farmácias face ao ano anterior nessa situação (ANTÃO, GRENHA, 2016).

\section{Convergências e divergências entre os pontos regulatórios levantados}

$\mathrm{Na}$ Tabela 2, de modo didático, buscou-se sumarizar os pontos de convergência e de divergência identificados entre a legislação regulatória brasileira e portuguesa para o varejo farmacêutico.

Tabela 2. Quadro Comparativo entre as regulamentações de Brasil e Portugal

\begin{tabular}{lcc}
\hline \multicolumn{1}{c}{ Regulamentação } & Brasil & Portugal \\
\hline Propriedade exclusiva de Farmacêutico & Não & Sim (até 20o7) \\
\hline Limite de Farmácias por proprietário & Não & Sim (4) \\
\hline Abertura de nova Farmácia & Não & Sim (licitação) \\
\hline Quantidade de Farmácia por habitante & Não & Sim \\
\hline Distância mínima entre Farmácias & Não & Sim \\
\hline Encerramento de Farmácia & Regras Regionais & Regra Nacional \\
\hline $\begin{array}{l}\text { Produtos não medicamentos na } \\
\text { Farmácia }\end{array}$ & Não & Sim (Isentos de Prescrição) \\
\hline Medicamentos fora da Farmácia & &
\end{tabular}




\begin{tabular}{|c|c|c|}
\hline $\begin{array}{l}\text { Controle de Preço dos medicamentos } \\
\text { pelo Governo }\end{array}$ & Sim & Sim \\
\hline
\end{tabular}

Fonte: Resultados originais da pesquisa

\section{CONCLUSÃO}

Como conclusão das informações levantadas, foram identificadas implicações gerenciais e sociais.

Como implicações gerenciais foi observado que, por conta da diferença de regulamentação, o modelo de grandes redes no Brasil, detentor de boa parte do faturamento do segmento, seria um empecilho para a internacionalização para Portugal.

Foi observado, ainda, estudos (SANTOS, ROSA, 2018) que relatam o desinvestimento e a insolvência de um número crescente de farmácias portuguesas, decorrentes em grande parte pela política de coparticipação ali praticada.

Os bons números do setor no Brasil, figurando atualmente como 6o colocado no Ranking dos Mercados Farmacêuticos, atraem novos entrantes e investimentos.

Nota-se, também, que o Brasil é um mercado em expansão, dado seu crescimento populacional, com possibilidade de expansão em regiões ainda não consolidadas.

Porém, recomenda-se um monitoramento do setor face uma possível saturação do

mercado de farmácias no Brasil caso mantenha-se uma expansão acelerada das grandes redes, assim como das redes independentes, que, ainda, geraria uma escassez de pontos comerciais para locação e consequente inflação nos aluguéis deles.

No entanto, dado que o Brasil não possui uma regulamentação sobre a quantidade de Farmácias/Drogarias por habitantes, como implicações sociais, podemos iniciar pela possibilidade de que a alta concorrência poderia gerar uma redução nos preços praticados no Brasil.

Não bastasse, com a expansão nas regiões brasileiras ainda não adensadas, poder-seia verificar a ampliação do acesso à Saúde em todo território nacional.

Mas, com o desinvestimento do Governo brasileiro nas políticas de coparticipação, a população passa gastar mais com Saúde.

Ponto de alerta fica, ainda, diante da projetada expansão do segmento, para eventual impacto na saúde da população brasileira diante da venda indiscriminada de medicamentos, que demandariam medidas governamentais para resguardar a saúde pública. 


\section{REFERÊNCIAS}

ALMEIDA, A.R.M.; REZENDE, L.P.; VALE, B.N. 2017. A saturação do mercado de farmácias e drogarias em Gurupi-TO: Uma análise de marketing. Revista Científica do Norte Goiano; Volume V (I), I37-153.

Associação Brasileira de Redes de Farmácias e Drogarias [ABRAFARMA]. 2018. Índices ABRAFARMA 2018. Disponível em: 〈https://www.abrafarma.com.br/numeros $>$. Acesso em: I4 maio 20I9.

Associação da Indústria Farmacêutica de Pesquisa [INTERFARMA]. 2018. Guia 2018. Dados do Setor. Disponível em 〈https://www.interfarma.org.br/guia/guia2018/dados_do_setor/>. Acesso em: I4 maio 2019.

Autoridade Nacional do Medicamento e Produtos de Saúde, I. P. [INFRAMED]. 2019. Abertura de nova farmácia. Disponível em: 〈http://www.infarmed.pt/web/infarmed/entidades/licenciamentos/farmacias/abertura . Acesso em: 14 maio 2019

ANTÃO, A.A; GRENHA, C.M. 20I6. Sustentabilidade da dispensa de medicamentos nas farmácias em $\quad$ Portugal. Disponível em <https://www.revistasauda.pt/SiteCollectionDocuments/Documentos/Sustentabilidade \%20da\%2odispensa\%20de\%2omedicamentos\%20nas\%2ofarm\%C3\%Aicias\%20em\%20Portu gal.pdf >. Acesso em: 13 jun. 2019.

Base de Dados Portugal Contemporâneo [PORDATA]. 2019. Farmácias: número. Disponível em: <https://www.pordata.pt/Portugal/Farm\%C $3 \%$ Aicias $+n \% \mathrm{C}_{3} \% \mathrm{~B} A m e r o-$ I53>. Acesso em: 13 jun. 2019.

BRANDÃO, A. Desregulamentação: O furacão que revolveu o setor farmacêutico, em Portugal.

em <http://www.cff.org.br/sistemas/geral/revista/pdf/r26/o25a029_entrevista_carlos_maurA cio_barbosa.pdf $>$. Acesso em: 13 jun. 2019.

CARVALHO, M.S.D.S. 2013. A gestão em farmácia comunitária: Metodologias para optimizar a rentabilidade da farmácia. Dissertação de Mestrado em Ciências Farmacêuticas - Universidade Lusófona de Humanidades e Tecnologias. Lisboa, Portugal.

Centro de Estudos e Investigação em Saúde da Universidade de Coimbra [CEISUC]. 2006. Estudo do sector das farmácias em Portugal. Disponível em: 〈https://www.ordemfarmaceuticos.pt/pt/publicacoes/estudos/estudo-do-sector-dasfarmacias-em-portugal/>. Acesso em: I4 maio 2019.

Conselho Federal de Farmácia [CFF]. 2018. Dados 2018. Disponível em $\langle$ http://www.cff.org.br/pagina.php?id=8or\&menu=8or\&titulo=Dados+20I8〉. Acesso em: I4 maio 2019 . 
Conselho Federal de Farmácia [CFF]. 2019. Legislação Geral. Disponível em $\left\langle\right.$ http://www.cff.org.br/pagina.php?id=57\&menu=5\&titulo=Legisla $\% \mathrm{C}_{3} \% \mathrm{~A}_{7} \% \mathrm{C}_{3} \% \mathrm{~A}_{30} \mathrm{G}$ eral>. Acesso em: i8 jun 2019.

Federação Brasileira das Redes Associativistas e Independentes de Farmácias [FEBRAFAR]. 2018. Grandes Redes Versus Pequenas Farmácias. Disponível em: 〈https://www.febrafar.com.br/grandes-redes-versus-pequenas-farmacias/〉. Acesso em: I5 jun. 2019.

Federação Brasileira das Redes Associativistas e Independentes de Farmácias [FEBRAFAR]. 2019. Farmácia Online ainda não é realidade. Disponível em: < https://www.febrafar.com.br/farmacia-online-ainda-nao-e-realidade/>. Acesso em: is jun. 2019 .

FUENTES, A. 2017. Conhece aquela do brasileiro? 8 motivos para Portugal rir do Brasil. Disponível em < https://veja.abril.com.br/blog/impavido-colosso/conhece-aquela-dobrasileiro-8-motivos-para-portugal-rir-do-brasil/>. Acesso em: o7 ago. 2019.

Fundação Instituto de Administração [FIA]. 20I8. Varejo Farmacêutico no Brasil [Guia Completo 2018]. Disponível em <https://fia.com.br/blog/varejo-farmaceutico/>. Acesso em: 15 jun. 2019.

GIL, A.C. 2018. Como elaborar projetos de pesquisa. 6ed. Atlas, São Paulo, SP, Brasil.

GUEDES, M.P. 2016. O futuro do varejo farmacêutico brasileiro em 2025:Uma visão prospectiva sob o âmbito competitivo, regulatório e de consumo. Dissertação de Mestrado em Gestão de Negócios. Fundação Instituto e Administração. São Paulo, SP, Brasil.

Guia da Farmácia - Revista Dirigida aos Profissionais de Saúde [GUIA DA FARMÁCIA]. 2019. Ranking Abrafarma: Raia Drogasil lidera varejo farma em faturamento. Disponível em: 〈https://guiadafarmacia.com.br/ranking-abrafarma-raia-drogasil-libera-varejofarma/ >. Acesso em: I4 maio 2019.

Instituto Humanitas Unisinos. 2019. Farmácia Popular deixa de atender 7 milhões em 2 anos. Disponível em: 〈https://www.brasildefato.com.br/2019/o4/ı/farmacia-popular-deixa-deatender-7-milhoes-em-2-anos/>. Acesso em: 12 ago. 2019.

IQVIA. 20I8. Overview Farmácias Portugal. Disponível em 〈https://www.iqvia.com/ptpt/locations/portugal/pharmacy-overview-portugal-dezembro-2018 >. Acesso em: i3 jun. 2019 .

JUNQUEIRA, D. 2019. Alvo de cortes de Temer, programa Farmácia Popular deixa de atender 7 milhões. Disponível em:

https://wwwi.folha.uol.com.br/cotidiano/2019/o4/alvo-de-cortes-de-temer-programafarmacia-popular-deixa-de-atender-7-milhoes.shtml>. Acesso em: 12 ago. 2019.

KOTLER, P. 200o. Administração de Marketing: a edição do novo milênio. Pearson Prentice Hall, São Paulo, SP, Brasil. 
KOTLER, P.; KELLER, K.L. 2006. Administração de marketing. Ized. Pearson Prentice Hall, São Paulo, SP, Brasil.

KOTLER, P.; KELLER, K.L. 20ı2. Administração de marketing. I4ed. Pearson Prentice Hall, São Paulo, SP, Brasil.

LUSA, M.C. Número de farmácias em insolvência mais do que triplicou em cinco anos. Disponível em: 〈https://observador.pt/2018/or/ro/numero-de-farmacias-em-insolvenciamais-do-que-triplicou-em-cinco-anos/>. Acesso em: Io abr. 2019.

MADEIRA, A.B; SILVEIRA, J.A.G. 20I2. Internacionalização de empresas de varejo. p.531542. In: ANGELO,C.F; NIELSEN, F.A.G; FOUTO,N.M.M.D. Manual de Varejo no Brasil. Saint Paul Editora, São Paulo, SP, Brasil.

MALHOTRA, N.K. 2012. Pesquisa de marketing: uma orientação aplicada. 6ed. Bookman, Porto Alegre, RS, Brasil.

MAlHOTRA, N.K. 2oIr. Pesquisa de marketing: foco na decisão. zed. Pearson Prentice Hall, São Paulo, SP, Brasil.

MATTAR, F.N. 20I4. Pesquisa de marketing: metodologia, planejamento, execução e análise. 7ed. Elsevier, Rio de Janeiro, RJ, Brasil.

MEZZAROBA, O.; MONTEIRO, C.S. 2009. Manual de metodologia da pesquisa no direito. sed. Saraiva, São Paulo, SP, Brasil.

MOTTA, D.A. 2014. A liderança essencial. Virgilae, São Paulo, SP, Brasil.

NASCIMENTO, L.P. 2012. Elaboração de projetos de pesquisa: monografia, dissertação, tese e estudo de caso, com base em metodologia científica. Cengage Learning, São Paulo, SP, Brasil.

PEREIRA, C. 2017. Entenda por que o Brasil tem uma "overdose" de farmácias. Disponível em: <https://gauchazh.clicrbs.com.br/comportamento/noticia/2017/o5/entenda-por-queo-brasil-tem-uma-overdose-de-farmacias-978680o.html>. Acesso em: Io abr. 2019.

PILATI, J.I. 200o. Teoria e prática do direito comparado. OAB/SC, Florianópolis, SC, Brasil.

Portugal. 1933. Decreto-Lei no 23422, de 29 de Dezembro de 1933. Estabelece o regime jurídico das farmácias de oficina. Disponível em: < https://dre.pt/web/guest/pesquisa//search/325884/details/normal?q=decreto+lei+23422>

Portugal. 2007. Decreto-Lei no 307, de 31 de Agosto de 2007. Estabelece o regime jurídico das farmácias de oficina. Disponível em: <https://data.dre.pt/eli/declei/307/2007/p/cons/20161108/pt/html> 
SANTOS, A.S.; ROSA, S.M. 2019. De negócio milionário a sector em crise: um retrato das farmácias em números. Disponível em: 〈https://expresso.pt/economia/2018-o8-16-Denegocio-milionario-a-sector-em-crise-um-retrato-das-farmacias-em-numeros \#gs.4j722b>.

Acesso em: Io abr. 2019.

Serviço Brasileiro de Apoio às Micro e Pequenas Empresas [SEBRAE]. 2019. Guia de Farmácias. or - Aspectos Legais e Fiscais das farmácias, drogarias e farmácias de manipulação. Disponível em <https://bibliotecas.sebrae.com.br/chronus/ ARQUIVOS_CHRONUS/bds/bds.nsf/58e979c8bd97a76e6a9ce685d73b9b2a/\$File/5819.p df $>$. Acesso: I4 mai. 2019.

Serviço Nacional de Saúde [SNS]. 2018. Retrato da Saúde 2018. Disponível em 〈https://www.sns.gov.pt/retrato-da-saude-2018/>. Acesso em: I2 ago. 2019.

SILVA, P.J.S.S.S. 20ı6. A farmácia comunitária Portuguesa - O paradigma do marketing na satisfação e fidelização dos utentes. Dissertação de Mestrado em Especialização de Gestão/MBA. Universidade Aberta. Lisboa, Portugal.

WEBER, W. 20Ir. Grupos estratégicos: Estudo da concorrência no setor farmacêutico brasileiro. Tese de Doutorado em Administração, Faculdade de Economia, Administração e Contabilidade, Universidade de São Paulo. São Paulo, SP, Brasil.

The World Bank [World Bank]. 2019. Population, total. Brazil e Portugal. Disponível em: <https://databank. worldbank.org/reports.aspx? source=2\&country=BRA,PRT\#>. Acesso em: 13 jun. 2019.

The World Bank [World Bank]. 2019. Life expectancy at birth, total (years). Brazil e Portugal. Disponível em: < https://data.worldbank.org/?locations=BR-PT>. Acesso em: o7 ago. 2019.

The World Bank [World Bank]. 2019. Inflation, consumer prices (annual \%). Brazil e Portugal. Disponível em: 〈https://data.worldbank.org/indicator/FP.CPI.TOTL.ZG?locations=BR-PT $>$. Acesso em: 07 ago. 2019.

The World Bank [World Bank]. 2019. GNI per capita, PPP (current international \$). Brazil e Portugal. Disponível em: 〈https://data.worldbank.org/indicator/NY.GNP.PCAP.PP.CD?locations=BR-PT $>$.

Acesso em: 07 ago. 2019.

The World Bank [World Bank]. 2019. Unemployment, total (\% of total labor force) (national estimate). Brazil e Portugal. Disponível em: 〈https://data.worldbank.org/indicator/SL.UEM.TOTL.NE.ZS?locations=BR-PT>.

Acesso em: 07 ago. 2019.

The World Bank [World Bank]. 2019. Domestic credit provided by financial sector (\% of GDP). Brazil e Portugal. Disponível em: 
〈https://data.worldbank.org/indicator/FS.AST.DOMS.GD.ZS?locations=BR-PT〉. Acesso em: 07 ago. 2019.

The World Bank [World Bank]. 2019. Current health expenditure per capita, PPP (current international \$). Brazil e Portugal. Disponível em: $\langle$ https://data.worldbank.org/indicator/SH.XPD.CHEX.PP.CD?locations=BR-PT $>$. Acesso em: 07 ago. 2019. 